\title{
A death in the family
}

\section{Reflections on the Terri Schiavo case}

\section{Charles Weijer}

Published at www.cmaj.ca on Apr. 1, 2005. Revised on Apr. 6, 2005.

$\mathrm{T}$ erri Schiavo, a 41-year-old Florida woman who was in a persistent vegetative state for the 15 years before her death on Mar. 31, 2005, was at the centre of a political, legal and media tempest over the removal of a feeding tube. Hyperbole has run high on both sides of the controversy. Religious conservatives have decried the removal of her feeding tube as a "mortal sin"; defenders of a "right to die" have claimed that "Congress will now go trampling into the most, private, personal and painful decisions families must make." At the centre of the storm lay Terri Schiavo, her husband and her parents - all grievously struck by tragedy 15 years ago. Unable to agree on how to move forward, Schiavo's husband and parents sought remedy in the courts.

On Feb. 25, 1990, Terri Schiavo suffered a cardiac arrest caused by hypokalemia induced by an eating disorder. ${ }^{2}$ Severe anoxic encephalopathy ensued. Several months after the incident, computed tomography revealed severe atrophy of both cerebral hemispheres, and electroencephalography showed no evidence of cortical activity. Clinically, Schiavo stabilized into a persistent vegetative state, a state of eyes-open unconsciousness with sleep-wake cycles in which patients are unaware of themselves or their environment. Despite the poor prognosis for meaningful neurologic recovery, standard and experimental therapies were administered, to no effect, for 3 years. Only then did her husband, Michael Schiavo, accept the diagnosis of her neurologists that her condition was irreversible. Recalling a statement that his wife had once made - "I don't want to be kept alive on a machine" - he refused further lifesustaining measures on her behalf. ${ }^{2}$ However, her parents, Bob and Mary Schindler, never accepted the diagnosis of persistent vegetative state and vigorously opposed their son-in-law's decision. Seven years of litigation generated 30 legal opinions, all supporting Michael Schiavo's decision on कo his wife's behalf. ${ }^{3}$

Now that Terri Schiavo's life has drawn to a close, we might ask what lessons can be learned from this sad case. How ought decisions to be made on behalf of those in persistent vegetative states? How ought we to deal with families who disagree as to the right decision in these cases?

Adults capable of making their own decisions have an unfettered right in Canada and the United States to refuse unwanted medical treatment, including the provision of artificial nutrition and hydration. ${ }^{3}$ When an adult is no longer able to make decisions for himself or herself, a surrogate decision-maker must take over that role. Although details of the law vary from province to province, the surrogate decision-maker is typically the spouse, adult child, parent or other close relation of the incapable patient. The law protects incapable adults by constraining the scope of surrogate decision-making. The surrogate must decide as the patient himself or herself would have decided, on the basis of previous statements or expressed values, or, should these not be known, in the best interest of the patient. Thus, consent or refusal by a surrogate decision-maker is in itself insufficient without a clear justification.

I have argued before in the pages of CMAJ that legitimate decisions on behalf of patients in a persistent vegetative state may differ from case to case. ${ }^{4}$ Many - perhaps most - Canadians would not wish to have their life preserved by artificial means in a persistent vegetative state. When these wishes are expressed in a living will or in informal statements to family members or friends, or reflected more generally in the life values of the patient, the surrogate decision-maker may reasonably infer that the patient would not have wished his life prolonged by artificial means and accordingly refuse such treatment. Thus, as reflected by the unanimity of legal decisions, Michael Schiavo properly discharged his obligations as his wife's surrogate decisionmaker when he refused the artificial provision of nutrition and hydration on the basis that she had stated to him in the past, "I don't want to be kept alive on a machine."

However, in some cases patients have a deep religious commitment to preserving life. Relying on a living will, previously expressed statements or the religious beliefs of the patient, the surrogate may with equal legitimacy decide in favour of continuing life-preserving interventions. Within the bounds of available resources, this decision also ought to be respected. ${ }^{4}$ Most difficult are cases in which the wishes of the patient are unknown and a determination must be made purely in the best interests of the patient.

Bioethics commentary on the Terri Schiavo case has been, as one would expect, prominent in the media in re- 
cent weeks. The overwhelming message from bioethicists is that widespread use of living wills would prevent disputes like this from happening. For instance, Dr. Linda Emanuel said on The NewsHour with Fim Lebrer that "living wills are for everyone. They are analogous in many ways to a safety belt. They don't solve everything but they certainly minimize the damage." Although living wills can usefully clarify the wishes of a patient who has become incompetent, they suffer from a number of limitations. First, living wills are limited by our inability to fully anticipate future medical circumstances. Such documents lack specificity, and therefore they require the assistance of family members to be interpreted. Just as Terri Schiavo's family disagreed as to the accuracy of the medical diagnosis, it is also possible that they would have disagreed as to how to interpret provisions in a living will in the event that Terri Schiavo had executed one. Second, only a minority of the population possess living wills. Although the case of Terri Schiavo will certainly inspire some to fill out living wills, it seems a safe bet that few in their second or third decade of life - the group most likely to survive grievous injury and enter a persistent vegetative state - will do so.

Bioethics commentators have missed an important moral question posed by the Terri Schiavo case, namely, how to deal with familial disagreement. Families commonly disagree over how best to care for a loved one, and no doubt there will be future cases in which families in similarly unfortunate circumstances are faced with the challenge of preventing disagreement or managing it when it occurs. Families share a bond in which each member has a duty to care for the others. ${ }^{6}$ Legal solutions to cases of familial dispute are inherently divisive because they rest on the procedural solution of privileging one family member as "the decision-maker." Accordingly, they ought to be invoked only as a last resort. When a patient is incapable of directing his or her own care, regular meetings between the health care team and the family have a dual effect: they ensure that everyone has the same information, and they affirm the participation of all in the decision-making process. If a dispute arises, it is important to affirm the legitimate moral role played by all family members in seeking what is best for their loved one. Giving the family time to seek consensus on their own, trials of therapy with clear treatment goals, negotiation and arbitration can all be used to facilitate consensus. Some familial disputes will, in the end, require a legal solution. As the case of Terri Schiavo illustrates all too clearly, such solutions come at a potentially heavy cost: the double tragedy of a death in a family, and the death of a family.

Charles Weijer is an associate professor of Bioethics, Medicine, and Surgery and adjunct professor of Philosophy at Dalhousie University, Halifax, N.S.

Competing interests: Dr. Weijer's research is supported by an Investigator Award and Operating Grant from the Canadian Institutes of Health Research.

Acknowledgements: I am indebted to Kris Andrews, BKin, Anthony Belardo, MA, and Paul Miller, MA, MPhil, JD, for illuminating discussions regarding this case.

\section{References}

1. Koring P. Judge reserves decision on Shiavo feeding tube. Globe \& Mail 2005 Mar 22;Sect A13.

2. Quill TE. Terri Schiavo - a tragedy compounded. N Engl 7 Med [early online release]. Available: www.nejm.org (accessed 2005 Mar 29).

3. Annas GJ. "Culture of life" politics at the bedside - the case of Terri Schiavo. $N$ Engl 7 Med [early online release]. Available: www.nejm.org (accessed 2005 Mar 29).

4. Weijer C. Cardiopulmonary resuscitation for patients in persistent vegetative state: futile or acceptable. CMA7 1998:158;491-3.

5. Lehrer J. Living wills. NewsHour Online 2005 Mar 22. Available: www.pbs.org /newshour/bb/law/jan-june05/wills_3-22.html (accessed 2005 Mar 31).

6. Freedman B. Respectful service and reverent obedience: A Jewish view on making decisions for incompetent parents. Hastings Center Report 1996;26(4):31-7.

Correspondence to: Dr. Charles Weijer, Department of Bioethics, Dalhousie University, 5849 University Ave., Halifax, NS B3H 4H7; fax 902 494-3865; charles.weijer@dal.ca 